\title{
Systematics and phylogeography of the Dysdera erythrina species complex (Araneae, Dysderidae) in Sardinia
}

\author{
Miquel A. Arnedo ${ }^{1, \dagger}$, Fulvio Gasparo ${ }^{2, \ddagger}$, Vera Opatova ${ }^{1,3, \S}$ \\ I Departament de Biologia Animal and Biodiversity Research Institute, Universitat de Barcelona, Av. Diagonal \\ 645, Barcelona 08028, Spain 2 Via Vittoria Colonna 8, I-3124 Trieste, Italy 3 Department of Zoology, Facul- \\ ty of Science, Charles University in Prague, Viničná 7, CZ-128 44 Prague 2, Czech Republic \\ † urn:lsid:zoobank.org:author:0148CECC-OBCF-469F-8614-F4A447C26408 \\ † urn:lsid:zoobank.org:author:F65C1400-2AEA-42BE-8886-0A4B6C6789B0 \\ § urn:lsid:zoobank.org:author:FEBF8306-E7CD-4597-A685-26B41975CB1B
}

Corresponding author: Miquel A. Arnedo (marnedo@ub.edu, marnedo@gmail.com)

Academic editor: Jason Dunlop | Received 12 March 2009 | Accepted 19 June 2009 | Published 29 July 2009

urn:lsid:zoobank.org:pub:83634493-F32F-4AA7-8E38-39509131E706

Citation: Arnedo MA, Gasparo F, Opatova V (2009) Systematics and phylogeography of the Dysdera erythrina species complex (Araneae, Dysderidae) in Sardinia. In: Stoev P, Dunlop J, Lazarov S (Eds) A life caught in a spider's web. Papers in arachnology in honour of Christo Deltshev. ZooKeys 16: 319-345. doi: 10.3897/zookeys.16.128

\begin{abstract}
Sardinia is the second largest island in the Mediterranean and, together with Corsica and nearby mainland areas, one of the top biodiversity hotspots in the region. The origin of Sardinia goes back to the opening of the western Mediterranean in the late Oligocene. This geological event and the subsequent Messinian Salinity Crisis and Pleistocene glacial cycles have had a major impact on local biodiversity. The Dysdera woodlouse hunter spiders are one of the most diverse ground-dweller groups in the Mediterranean. Here we describe the first two species of this genus endemic to Sardinia: Dysdera jana sp. n. and Dysdera shardana sp. n. The two species show contrasting allopatric distribution: D. jana sp. n. is a narrow endemic while $D$. shardana sp. n. is distributed throughout most of the island. A multi-gene DNA sequence phylogenetic analysis based on mitochondrial and nuclear genes supports the close relationships of the new species to the type species of the genus Dysdera erythrina. Age estimates reject an Oligocene origin of the new Dysdera species and identify the Messinian Salinity Crises as the most plausible period for the split between Sardinian endemics and their closest relatives. Phylogeographic analysis reveals deep genetic divergences and population structure in Dysdera shardana sp. n., suggesting that restriction to gene flow, probably due to environmental factors, could explain local speciation events.
\end{abstract}

Copyright Miquel A.Arnedo et al. This is an open access article distributed under the terms of the Creative Commons Attribution License, which permits unrestricted use, distribution, and reproduction in any medium, provided the original author and source are credited. 


\section{Keywords}

Taxonomy, phylogeny, DNA sequencing, Mediterranean biogeography, phylogeography

\section{Introduction}

The Mediterranean basin is one of the Earth's biodiversity hotspots for conservation priority (Myers et al. 2000). A dynamic and tumultuous geological history ranks high among the main factors responsible for the outstanding diversity of the region. The island of Sardinia constitutes a good example of this ever-changing geological landscape. At the beginning of the Oligocene ( -30 million years ago, m.a.), several continental microplates, including present-day Sardinia, Corsica, the Balearic Islands, Calabria, the Kabylies and the Betic-Rift Cordillera, broke off from the north-eastern Iberian Peninsula as a result of geological back-arc extension processes, and started drifting to their present-day location. During the first stage of the back-arc extension, the northern microplate assemblage (i.e., Sardinia, Corsica and Calabria) started drifting counter-clockwise with respect to the Eurasian plate and finally collided with the Apulian plate about 20-18 m.a. (Rosenbaum et al. 2002). There is no general consensus on the time of separation of Corsica and Sardinia. Some authors suggest that Sardinia broke off from Corsica 20 to 16 m.a. (Rosenbaum et al. 2002); while others consider that the process would not have been fully completed until about 9 m.a. (Alvarez 1972, 1974). The closing of the Miocene marine gateways between the Mediterranean Sea and the Atlantic Ocean, 5.96 m.a., caused a large drop in the Mediterranean water level (Blondel and Aronson 1999; Krijgsman et al. 1999) and the emergence of land connections between Sardinia and northern Italy and southern France. The opening of the Strait of Gibraltar about 5.3 m.a. restored the water exchange between the Atlantic and Mediterranean basins, re-establishing effective isolation of the island ecosystems (Loget and Van Den Driessche 2006; Loget et al. 2005). Eustatic sea level changes as a result of Pleistocene glacial cycles could have connected Sardinia with Corsica, and with the mainland, via Elba. Sea level oscillations creating land bridges between Sardinia and Corsica from the Miocene until well into the Pleistocene (5.7 - 0.23 m.a.) have been additionally suggested (Arias et al. 1980).

Sardinia is the second largest island in the Mediterranean (Fig. 1), generally mountainous with a few coastal plains. The island's mountains are divided into three ranges that largely coincide with areas of high endemism, namely Mount Limbara on the north, the Gennargentu-Supramonte Massif on the central-eastern side, and the Sette Fratelli on the south-east (Grill et al. 2007). Additionally, a separate biogeographic region has been proposed for the Sulcis-Iglesiente territory in the south-western part of Sardinia, based on exclusive plant endemism and a unique blend of geolithologic, geomorphologic, paleogeographic, bioclimatic and vegetation features (Bacchetta et al. 2007). It is worth noting that the Tyrrhenian islands, Sardinia and Corsica, and the Maritime-Ligurian Alps, are among the regions with the highest level of narrow endemism in the Mediterranean basin (Medail and Quezel 1999). 


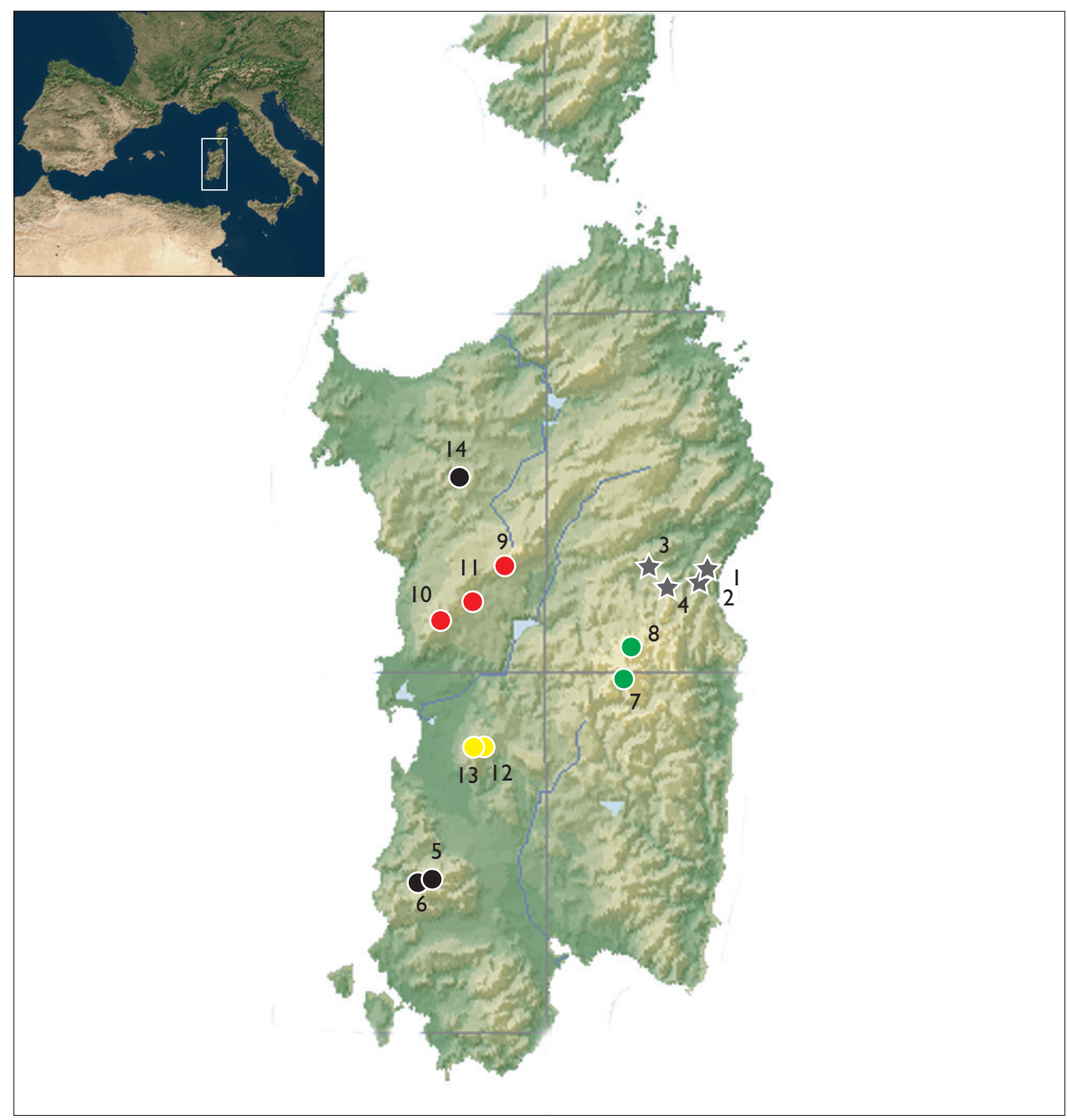

Figure I. Maps showing the location of Sardinia and known localities of the new species. Dysdera jana sp. n.: Nuoro: I Dorgali, 450 m, 22 km S of Dorgali, 500 m, 3 Supramonte di Oliena, 900 m, 4 Sa Oche, 7 km ESE of Oliena, 150 m. D. shardana sp. n.: Cagliari: 5 Fluminimaggiore, Is Arenas, 6 Fluminimaggiore, Tempio di Antas, Nuoro: 7 Aritzo, Castagneto Geratzia, 867 m, 8 Desulo, rd. to Fonni, 1146 m, 9 Macomer, Mt. S. Antonio. Oristano: 10 Cuglieri, rd. to San Leonardo 7 Fuentes, 587 m, I I S. Leonardo 7 Fuentes, 699 m, 12 Morgongiori, Is Benas recreation area, 566 m, I3 Morgongiori, Bruncu Mutzuis, 761 m, I4 Sassari: NW Torralba.

The woodlouse-hunter spiders of the genus Dysdera Latreille, 1804 include about 250 described species (Platnick 2009) of mostly nocturnal, wandering, ground-dwelling spiders. Although the geographic distribution of the genus includes most of the Western Palaearctic, it is especially diverse in the Mediterranean region, where it constitutes one of the most conspicuous components of the local ground arthropod fauna. The erythrina group was originally proposed by Deeleman-Reinhold and Deeleman 
(1988) to include the type species of the genus, Dysdera erythrina (Walckenaer, 1802), as well as some other species described from the Iberian peninsula, which included $D$. fuscipes Simon, 1882, D. anonyma Ferrández, 1984 and D. veigai Ferrández, 1984. This group was proposed to be related to the crocata group, from which it would differ by the shape and size of the carapace and the chelicera, the spination pattern and the shape of the male bulb (male secondary copulatory structure, located on palpal tarsi). The great French arachnologist E. Simon described three subspecies of D. erythrina, namely $D$. erythrina lantosquensis Simon, 1882 from France, D. erythrina fervida Simon, 1882 from Corsica and the Balearic Islands and D. erythrina provincialis Simon, 1882 from France (Platnick 2009). Subsequently, Rezáč and collaborators (2007) have granted species status to $D$. lantosquensis, and suggested that the rest of the subspecies should also be considered different species.

Sardinia harbours a rich endemic Dysderidae fauna, which includes four Harpactea Bristowe, 1939 species, one Parachtes Alicata, 1964 and the monotypic cave-dwelling endemic genus Sardostalita Gasparo, 1999 (Platnick 2009; Stoch 2003). Endemic Dysdera species have not been reported from Sardinia so far. The crocata group is represented by the synanthropic D. crocata C.L. Koch, 1839, D. ancora Grasshoff, 1959 and D. ventricosa Grasshoff, 1959, the latter two species also present in Sicily (Stoch 2003). Grasshoff (1959) reported the presence in Sardinia of D. kollari Doblika, 1853, a species previously reported from the eastern Adriatic coast (Chyzer and Kulczyński 1897) and northern Greece, and described the formerly unknown male (Grasshoff 1959) (it turned out to be a misidentification, see below; a drawing of the actual D. kollari male palp can be found in Gasparo 2004). However, the former citation has been suggested to refer to another species (Deeleman-Reinhold and Deeleman 1988). Finally, there is an early record of the presence of D. erythrina from Sardina (Costa 1885), which has not been subsequently confirmed to date.

In the present paper we confirm the presence of the erythrina group in Sardinia based on museum collections and newly collected material, and describe two new species, one of them including specimens previously misidentified as D. kollari. Phylogenetic position, time of origin and phylogeographic patterns of the new species are further investigated by means of molecular evidence.

\section{Methods}

\section{Taxonomy}

Morphological methods are described in detail in Arnedo and Ribera (1999) and Arnedo et al. (2000). Taxonomic descriptions follow the format of Arnedo and Ribera (1999). Specimens were examined using a Leica MZ16A stereoscopic microscope equipped with a Nikon DXM1200 digital camera and an ocular measuring graticule. Digital microscope images were edited using the Auto-Montage software package v.4 (Syncroscopy, Frederick, MD, USA)]. Male right palps were removed, cleaned by means of ultrasound 
and examined using either a HITACHI S-2300 Scanning Electron Microscope (SEM) (SCT, Universitat de Barcelona, Barcelona, Spain) operated at $15 \mathrm{kV}$. Left male palps were used for optic images and right palps were used for SEM images. All morphological measurements are given in millimetres. Eye diameters were taken from the spans of the lens. Carapace and abdomen measurements were taken in dorsal view, abdomen hairs were measured in lateral view, and cheliceral basal segment length was measured in lateral view. The prolateral groove of the chelicera was measured in dorsal view, by positioning the chelicera parallel to the background and measuring from the distal end of the margin to the beginning of the cheliceral lamina. The fang was measured in ventral view, from the basal segment condyl to the fang distal tip. The largest leg article lengths were measured in lateral view without detaching the legs from the specimen, by placing the article being measured in a perpendicular position. The female vulva was removed and muscle tissues were digested using a $\mathrm{KOH}(35 \%)$ solution before observation. Leg spination was recorded using the codification method fully described in Arnedo and Ribera (1997).

\section{Abbreviations used in the text and figures are as follows: Eyes}

AME anterior medial eyes;

PME posterior medial eyes

PLE posterior lateral eyes

Male copulatory bulb

T tegulum

DD distal division

IS internal sclerite

ES external sclerite

C crest

AC additional crest

AR arch-like ridge

LF lateral fold over lateral sheet between internal and external sclerites

L lateral sheet

LA lateral sheet anterior apophysis

AL additional lateral sheet at the internal border

P posterior apophysis

Female genitalia

DA dorsal arch

DF dorsal arch fold

$S \quad$ spermatheca

TB transversal bar

\section{Repositories}

CRBA Centre de Recursos de Biologia Animal, University of Barcelona

CG F. Gasparo personal collection.

MSNVR Museo Civico di Storia Naturale di Verona (P. Brignoli’s collection) 


\section{Molecular phylogeny}

Taxa analysed in the present study, along with locality information and the GenBank accession numbers of the sequenced genes are listed in Table 1. Fresh specimens of $D$. jana sp. n. were not available for DNA analysis. Phylogenetic relationships of $D$. shardana sp. n. were inferred from a taxonomic sample that included all subspecies of Dysdera erythrina, representatives of the erythrina group (D. cf. inermis), putative related species based on genitalia characteristics (D. lusitanica Kulczyński, 1915, D. valentina Ribera, 2004), as well as two members of the crocata group. D. adriatica Kulczyński, in Chyzer and Kulczyński, 1897 was used as an outgroup based on the results of Macías-Hernández et al. (2008). The inclusion of $D$. cf. inermis specimens from both sides of the Strait of Gibraltar provided a vicariant biogeographic point (opening of the strait 5.3 million years ago) to estimate lineage age, by assuming that the separation of Iberian and Moroccan populations of D. cf. inermis was the result of this geological event. The same assumption has been used to calibrate molecular phylogenies in Canarian Dysdera (Macías-Hernández et al. 2008), scorpions (Gantenbein 2004), beetles (Gómez-Zurita 2004) and newts (Carranza and Arnold 2003). A second data matrix was built to investigate phylogeographic patterns in $D$. shardana sp. $\mathrm{n}$. by sampling all freshly collected specimens amenable to DNA analyses, namely 14 specimens from localities in central Sardinia (Mt. Ferru, Mt. Arci, and Gennargentu).

Protocols for specimen handling, DNA extraction, amplification, and sequencing of the gene fragments followed those of Macías-Hernández et al. (2008). The following gene fragments were analyzed: mitochondrial genes cytocrome $c$ oxidase subunit I (cox1, 676 bp), 16S rRNA (16S), the complete tRNA leu UAG (L1) (16S+L1, $387-$ $546 \mathrm{bp}$ ), NADH dehydrogenase subunit I (nad1, $362 \mathrm{bp}$ ), and the nuclear genes $28 \mathrm{~S}$ rRNA (28S, 620-768 bp) and histone H3 (H3, 328 bp). Sequences were edited and handled using the computer program GENEIOUS v. 4.5 (Drummond et al. 2009). Alignment of the protein coding genes was trivial, since no length differences were observed and no indel events needed to be postulated. Sequences of 16S-L1 and $28 \mathrm{~S}$ were automatically aligned using the online version of the program MAFFT v. 5.8 (Katoh et al. 2005; Katoh et al. 2002) (manual strategy set to G-INS-i). Gaps were subsequently recoded as separate presence/absence characters with the aid of the program GapCoder (Young and Healy 2003) following Simmons and Ochoterena (2000), to minimise the effect of increasing the weight of overlapping multiple non-homologous gaps (Pons and Vogler 2006). Gene partitions were combined in a single data matrix using WINCLADA v.1.00.08 (Nixon 2002), with non-sequenced fragments scored as missing data.

Parsimony analyses of the data matrices were conducted with the program TNT v. 1.1 (Goloboff et al. 2003), using the following search strategy: 1,000 iterations of Wagner trees constructed with random addition of taxa and subsequent TBR branch swapping, holding five trees per iteration up to a total maximum of 10,000. Clade support was assessed via jackknife resampling using 1,000 replicates with individual heuristic searches consisting of 15 iterations of Wagner tree construction using random 


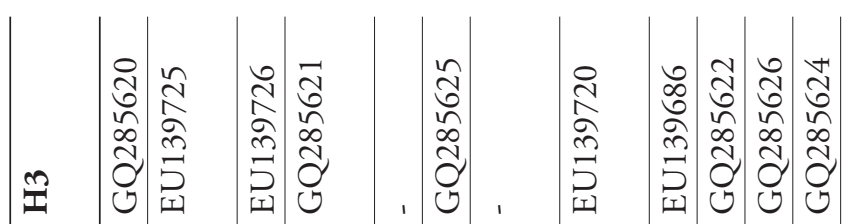

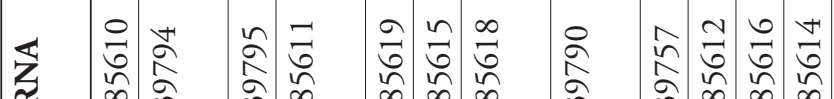

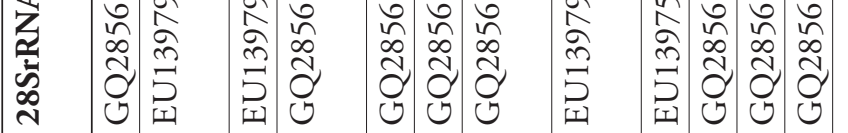

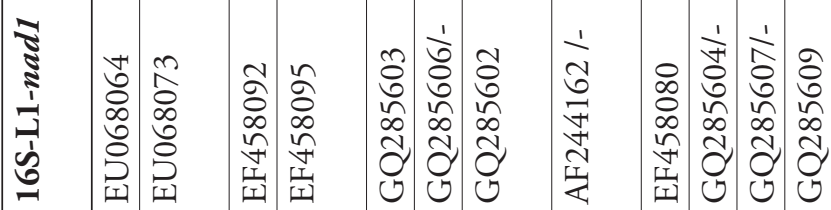

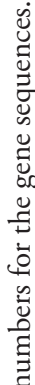

$\breve{\breve{v}}$

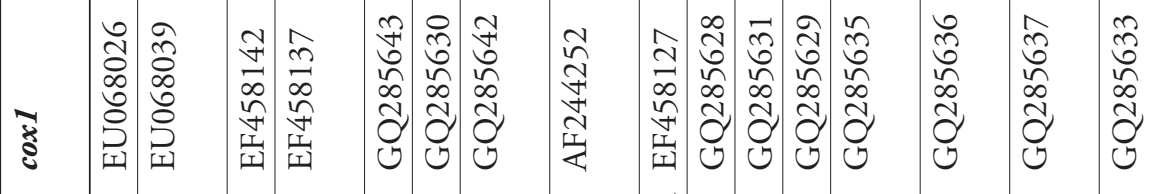

苞

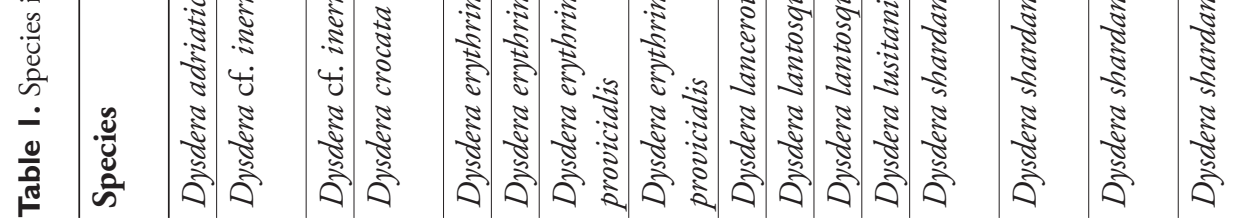




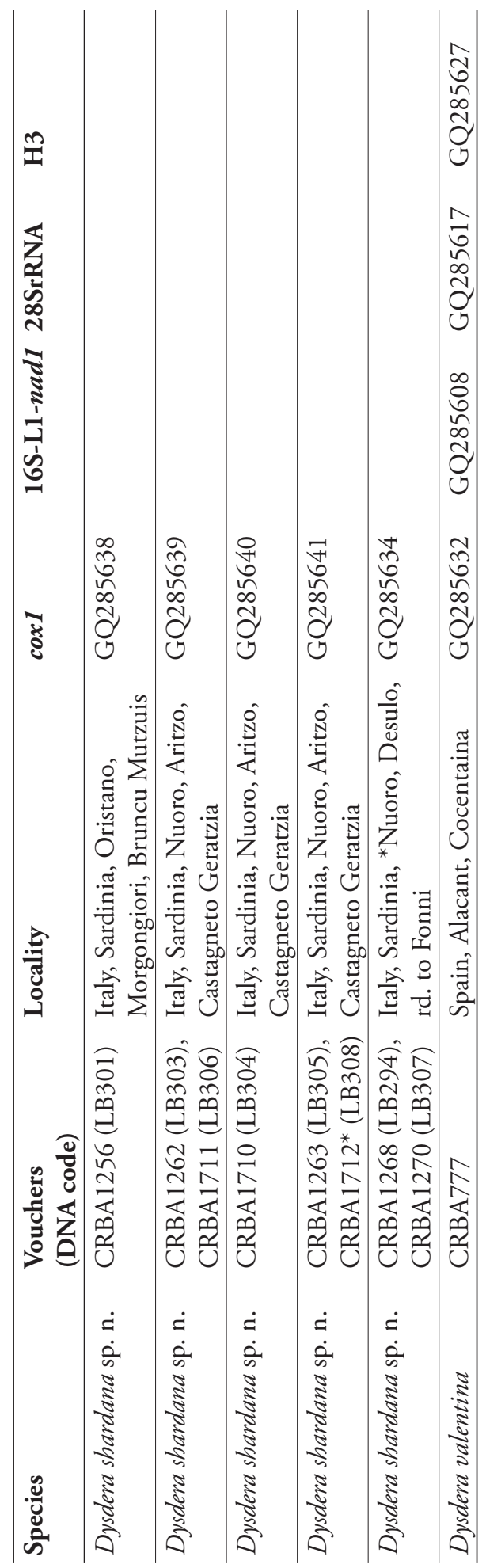


addition of taxa, holding five trees per iteration and an overall maximum of 10,000. The program jMODELTEST v. 0.1.1 (Posada 2008) was used to select the substitution model that best fits the data with the fewest parameters (including branch lengths as parameters), as indicated by the Akaike information criterion (AIC) (Akaike 1973).

Bayesian inference analyses were conducted with MRBAYES v.3.1.2 (Ronquist and Huelsenbeck 2003) and run remotely at the University of Oslo's Bioportal computer resources (http://www.bioportal.uio.no). The substitution models suggested by jMODELTEST were specified for each gene fragment and a standard discrete model was implemented for the gaps scored as absence/presence data (Nylander et al. 2004). The substitution estimates were allowed to vary independently between each partition. Two independent runs with four simultaneous MCMC (Markov Chain Monte Carlo) chains (one cold and three heated), each starting with random starting trees, were carried out simultaneously, sampling 1,000 generations until the standard deviation of the split frequencies of these two runs dropped below 0.01 (10 million generations). The program TRACER v. 1.4 (Rambaut and Drummond 2003) was used to ensure that the Markov chains had reached stationary by examining the effective sample size (ESS) values and also to determine the correct number of generations to discard as a burn-in for the analysis.

Maximum likelihood searches were conducted with the stand-alone version of the computer program RAxML v. 7.0.3 (Stamatakis 2006). Individual models of nucleotide substitution (GTR $+\Gamma+\mathrm{I}$, with default number of $\Gamma$-categories) were specified for each gene partition. The best trees were selected from 100 multiple inferences, and clade support was assessed by means of 100 non-parametric bootstrap resampled replicates of the original matrix.

Uncorrected genetic distances were estimated with MEGA v.4.0 (Tamura et al. 2007). A haplotype network was estimated from the cox 1 sequences using statistical parsimony, with probability connection limit set to $95 \%$, as implemented in the program TCS v. 1.21 (Clement et al. 2000).

Lineage age estimates were obtained with the aid of the computer program R8S v. 1.71 (Sanderson 2003). Branch lengths were re-estimated with the computer program RAxML forcing the topology obtained in the Bayesian analysis and specifying independent GTR+I+G substitution models for each gene fragment. The same program was used to generate 100 trees with the same topology by bootstrapped branch lengths, to generate confidence intervals of the times of divergence. Trees were rooted and very short or zero branch length branches were pruned with the help of the software TreeEdit v. 1.0 (Rambaut and Charleston 2001). A preliminary cross-validation analysis (Sanderson 2002) conducted with r8s selected the penalized likelihood method with a smoothing parameter value of 3200 and additive penalty function as the best options for reconstructing divergence times in our data set. Subsequent analyses with the preferred method were conducted to obtain optimal ages and corresponding confidence intervals. The resulting chronograms were visualised and manipulated with the assistance of the computer program FigTree v. 1.1.2 (http://tree.bio.ed.ac. $\mathrm{uk} /$ software/figtree/). 


\section{Results}

Results of the phylogenetic analyses conducted on all gene fragments concatenated in a single matrix are summarised in Fig. 2. Heuristic searches in TNT under equal weights yielded 3 trees of 2,015 steps. The best fit-models selected by the AIC for each data set were: $\mathrm{TrN}+\mathrm{I}+\mathrm{G}, \mathrm{TIM} 2+\mathrm{G}$, TIM2+G, GTR+G and TrNef+G for the cox1, 16S-L1, nad1, $28 \mathrm{~S}$ and $\mathrm{H} 3$, respectively. All analyses support the sister group relationship of $D$. shardana sp. $n$. with the present and former subspecies of D. erythrina. All analyses support the hypothesis that $D$. erythrina sensu stricto and $D$. erythrina provincialis are sister species, while the sister-species relationship of $D$. erythrina fervida and $D$. lantosquensis is only contradicted by the maximum likelihood analysis, although with low support. $D$. valentina is resolved as the sister group to the clade formed by $D$. shardana sp. $\mathrm{n}$. and D. erythrina sensu lato, although only the Bayesian analysis provides high support for this relationship. The phylogenetic analyses do not support a close relationship between either $D$. cf. inermis or D. lusitanica with the erythrina group. Parsimony partial analyses were run to assess the contribution of each data partition. The levels of support across the partial analyses were higher in the mitochondrial partition, followed by the $28 \mathrm{~S}$ gene fragment, and the histone 3 was the less resolved. Instances of incongruence among the partial analyses were, in general, poorly supported. The mitochondrial genes

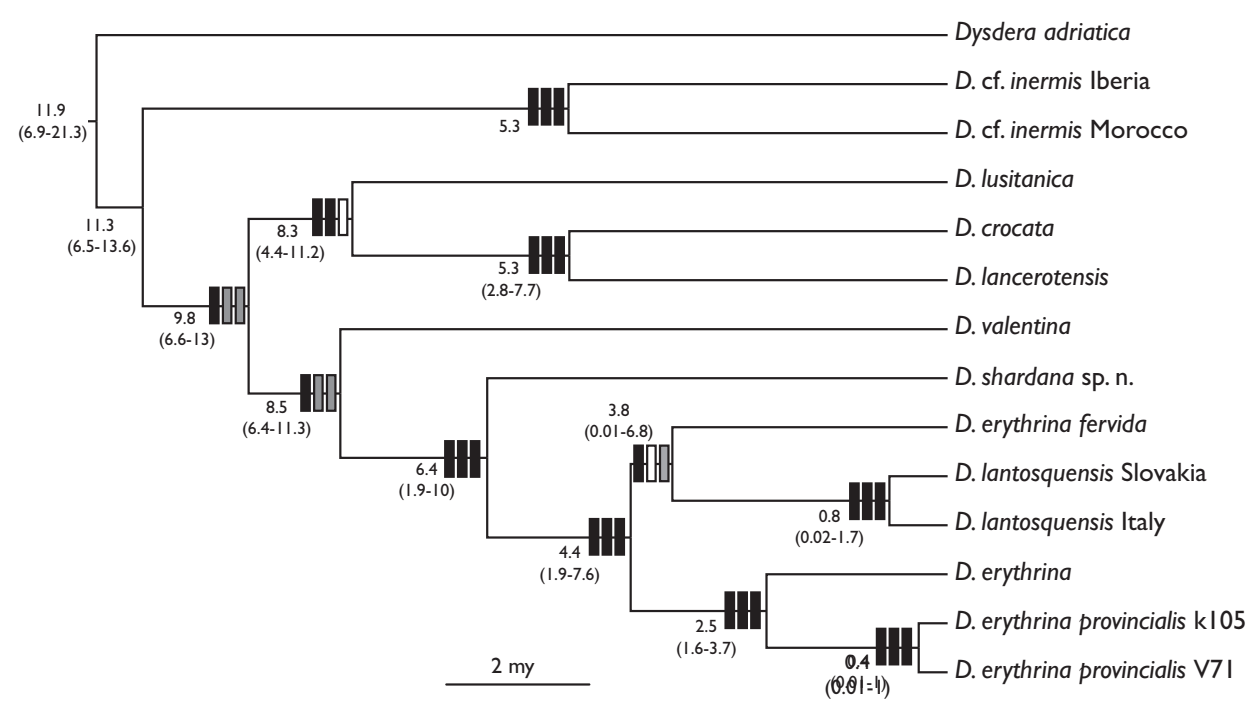

Figure 2. Chronogram of the species sampled in the present study, based on the preferred Bayesian tree obtained by simultaneous analyses of the cox 1, 16S, nad1, 28S and $\mathrm{H} 3$ partitions. Bars on branches denote support as follows: anterior bar refers to posterior probability, middle bar to maximum likelihood bootstrap support, posterior bar to parsimony jackknife support. Black bar: posterior probability $>0.95$ or ML bootstrap, Parismony jackknife $>70$, grey bar: posterior probability $<0.95$ or ML bootstrap, Parsimony jackknife $<70$, white bar: this particular clade was not recovered in the analyses. Numbers on branches are the age of the clade in millions of years before the present, estimated using penalized likelihood (set penalty=add, smoothing=3200), number in brackets refer to bootstrap confidence intervals. 

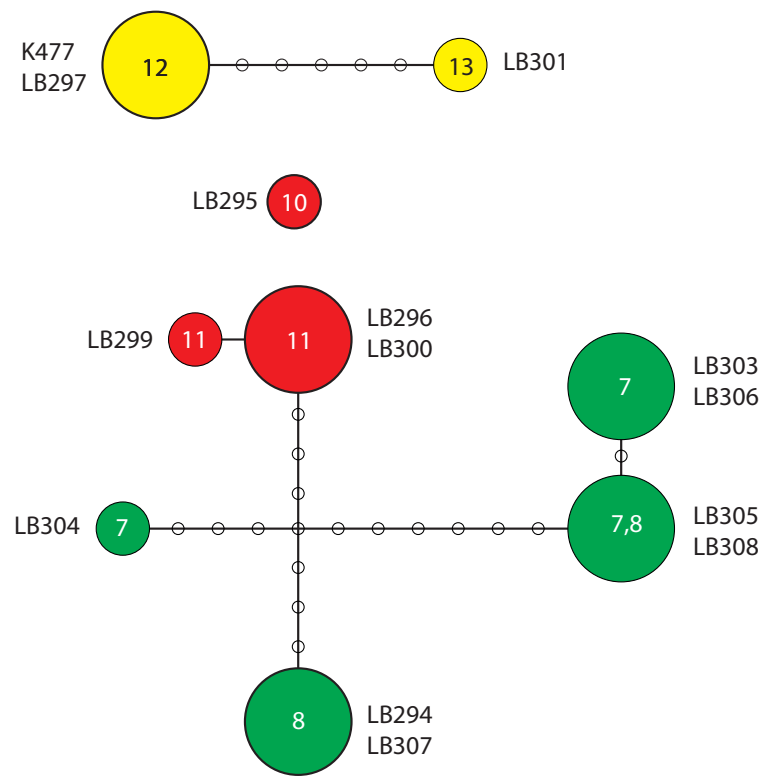

Figure 3. Haplotype network constructed using statistical parsimony (95\%). Dots on branches refer to missing haplotypes. Node size proportional to number of haplotypes (1 or 2$)$, nodes colour code and numbers inside refer to localities in Fig. 1.

yielded a single tree of 1800 steps, which mirrored results of the combined data set except for the position of $D$. valentina, which was sister to the $D$. lancerotensis $+D$. crocata clade (JS=60). The analysis of the $28 \mathrm{~S}$ gene fragment yielded 5 trees of 136 steps, the strict consensus of which supports the sister group relationship of $D$. valentina and the erythrina group, but does not resolve the position of $D$. shardana sp. n. In addition, $D$. lantosquensis formed a clade with $D$. erythrina and D. erythrina provincialis, although with low support (JS=62). The histone 3 fragment yielded a single tree of 63 steps. The erythrina group, $D$. shardana sp. n. excluded, was recovered as a clade (JS=60), but the haplotype k105 of D. erythrina provincialis grouped with $D$. fervida (JS=61). Lineage age estimates are also summarized in Fig. 2. The split of the ancestor of $D$. shardana sp. n. from the remaining species of the erythrina group is estimated at 6.4 m.a. although confidence intervals recovered are very wide (from 1.9 to 10 m.a.). The fourteen $D$. shardana sp. n. individuals sequenced for the cox 1 fragment resulted in 9 unique haplotypes. Statistical parsimony analysis of these resulted in two separate networks (Fig. 3) with strong geographic structure. The first network included the haplotypes sampled from Mt. Arci and the second network connected the haplotypes from Mt. Ferru, on the one hand, and those from Gennargentu, on the other. One specimen from Mt. Ferru remains isolated from any of the networks. Uncorrected genetic distances for the cox 1 gene between $D$. shardana haplotypes and between and within haplotypes of the species related to $D$. shardana sp. n. are summarized in Table 2. Mean genetic distance between $D$. shardana sp. n. haplotypes (3.8\%) was very similar to those observed in closely related species (4.6\% and 3.4\%. for D. lantosquensis and D. erythrina provincialis, respectively). 


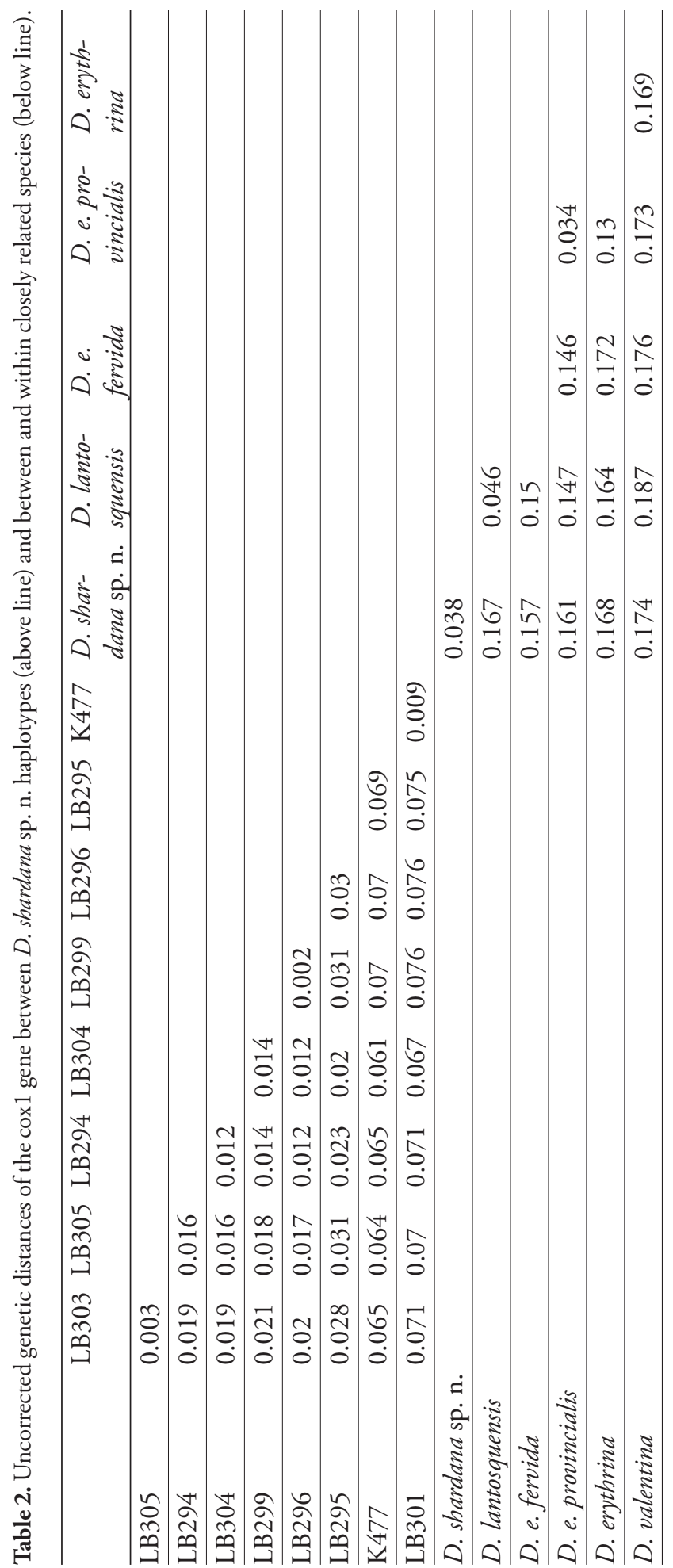




\section{Taxonomy}

\section{Dysdera Latreille, 1804}

Dysdera Latreille, 1804, type species Aranea erythrina Walckenaer, 1802: 224 (unspecified sex) by original designation, unspecified number of syntype specimens from France, surroundings of Paris (C. A. Walckenaer), repository unknown, supposedly lost.

Diagnosis. See Deeleman-Reinhold and Deeleman (1988).

Species included. The genus presently includes 248 species (Platnick 2009).

\section{Dysdera jana Gasparo \& Arnedo, sp. n.}

urn:lsid:zoobank.org:act:A4417862-62F2-433B-BCC9-E677576FF1C9

Figs 4, 6, 8, 10-11, 14-18

Type material. Holotype: male: Italy, Sardinia, Nuoro, Dorgali, along Viale J.F. Kennedy (=SS 125), 450 m, under Pinus, 17.X.1989; F. Gasparo (MSNVR AR 0010).

Paratypes: 1 male (CRBA001736) and 4 females (CRBA001736-1737, MSNVR AR 0011-12) same data and collector.

Additional material examined. Nuoro: $2 \mathrm{~km} \mathrm{~S}$ of Dorgali, $500 \mathrm{~m}$, under Quercus ilex, F. Gasparo leg. 20.X.1989, 2 우 (CG); Supramonte di Oliena, 900 m, under Quercus ilex, F. Gasparo leg. 13.X.1989, 2 우 (CG); Sa Oche (km 7 ESE of Oliena), 150 m, under Quercus ilex, F. Gasparo leg. 16.X.1989, 4 우우 (CG).

Diagnosis. Dysdera jana sp. n. can be distinguished from continental species of the erythrina group by the shape of the posterior-distal part of the tegulum, which is expanded in the continental species. It can also be distinguished from $D$. erythrina and D. erythrina provincialis by the lateral concave shape of the chelicera and a heavily wrinkled (foveate) carapace (Figs 4, 6). In addition, continental females of the erythrina group exhibit a characteristic hourglass-shaped spermatheca, which is very attenuated in D. jana sp. n. (Fig. 11). It differs from the other Sardinian species of the erythrina group by the spineless dorsal tibia 4 , the position and length of the finger-like process on the tip of the male bulb (compare Figs 15 and 21), and by the fusion of the anterior sclerotised stripes of the vulva VA (compare Figs 11 and 13).

Etymology. The name in apposition refers to the "Domus de janas", characteristic Sardinian tombs dug in the rock often according to a labyrinth architecture. Domus de Jana translates in Sardinian as "House of the fairies or of the witches". It also happens to be the name of the first author's goddaughter.

Description. Holotype male num. CRBA 1736. Figs 4, 6, 8, 14-18. Carapace (Fig. 4) $2.6 \mathrm{~mm}$ long; maximum width $2.09 \mathrm{~mm}$; minimum width $1.3 \mathrm{~mm}$. Orange, darkened at borders; foveate at borders, slightly wrinkled at middle, covered with small black grains. Frontal border roughly round, from $1 / 2$ to $3 / 5$ carapace length; anterior lateral borders parallel; rounded at maximum dorsal width, back lateral borders 
straight; back margin wide, straight. AME diameter $0.17 \mathrm{~mm}$; PLE $0.14 \mathrm{~mm}$; PME $0.12 \mathrm{~mm}$; AME slightly back from frontal border, separated from one another by about 1/2 diameter, close to PLE; PME very close to each other, about 1/3 PME diameter from PLE. Labium trapezoid-shaped, base wider than distal part; longer than wide at base; semicircular groove at tip. Sternum orange, darkened on borders; wrinkled; uniformly covered in slender black hairs.

Chelicerae $1.17 \mathrm{~mm}$ long, about 2/5 of carapace length in dorsal view; fang medium-sized, $0.97 \mathrm{~mm}$; basal segment proximal dorsal, ventral side scantly covered with piligerous granulations; concave-shaped in lateral view (Fig. 6). Chelicera inner groove medium-sized, about 2/5 cheliceral length; armed with three teeth and lamina at base; $\mathrm{B}=\mathrm{M}>\mathrm{D}$; D triangular, slightly below groove midpoint; $\mathrm{B}$ close to basal lamina; $\mathrm{M}$ close to B. Legs yellow. Lengths of male described above: fe1 $2.01 \mathrm{~mm}$ (all measurements in $\mathrm{mm}$ ); pa1 1.12; til 1.71; me1 1.43; ta1 0.46 ; total 6.73; fe2 1.94; pa2 1.07; ti2 1.63; me2 1.43; ta2 0.43 ; total 6.5 ; fe3 1.5 ; pa3 0.82; ti3 1.07 ; me3 1.17 ; ta3 0.41 ; total 4.97; fe4 1.89; pa4 1.02; ti4 1.58; me4 1.63; ta4 0.48; total 6.6; fe Pdp 1.12; pa Pdp 0.56; ti Pdp 0.61; ta Pdp 0.66; total 2.96; relative length: 1>4>2>3. Spination: leg1, leg2 spineless. Fe3d spineless; pa3 spineless; tb3d spines arranged in one band; distal 1.0 .0 ; tb3v with one terminal spine on prolateral margin. Fe4d spineless; pa4 spineless; tb $4 \mathrm{~d}$ spines spineless; tb $4 \mathrm{v}$ spines arranged in one band; proximal 0.1 .0 ; with one terminal spine at one leg and two on other one. Dorsal side of frontal legs, ventral side of palp covered with hairs. Claws with eight teeth or less; hardly larger than claw width.

Abdomen $4.13 \mathrm{~mm}$ long; cream-coloured; cylindrical. Abdominal dorsal hairs $0.05 \mathrm{~mm}$ long; thin, curved, not compressed, pointed; uniformly, thickly distributed.

Male copulatory bulb (Fig. 8) T slightly shorter than DD; external, internal distal borders sloped backwards. DD slightly bent in lateral view, clearly less than $45^{\circ}$; internal distal border not expanded. ES wider, more sclerotised than IS; IS continuous to
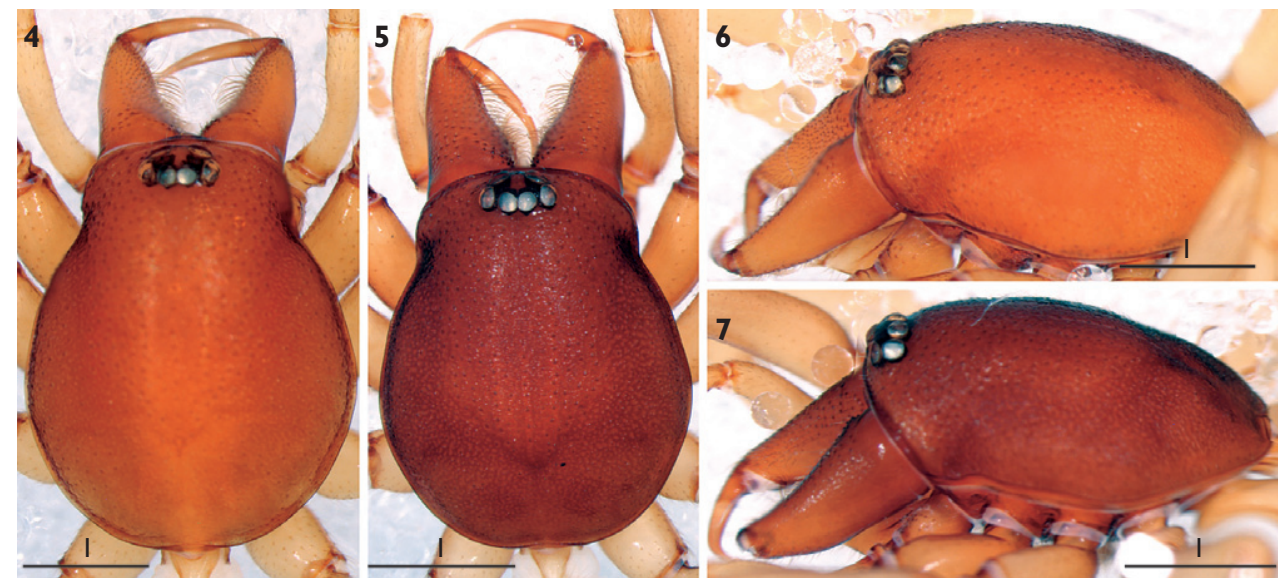

Figures 4-7. Carapace, dorsal view: 4 D. jana sp. n. holotype 5 D. shardana sp. n. holotype. Carapace, lateral view: $\mathbf{6}$ D. jana sp. n. holotype 7 D. shardana sp. n. holotype. 
tip. DD tip (12-15) straight in lateral view; AR present, parallel to DD; finger-like projection at distal end of the $\mathrm{AR}$ ridge base, as long as $\mathrm{AR}$ length. $\mathrm{C}$ absent. $\mathrm{AC}$ absent. LF absent. L reduced to distal part. LA absent. F absent. AL absent. P (Fig. 18) fused to $\mathrm{T}$; perpendicular to $\mathrm{T}$ in lateral view; lateral length about $1 / 4$ of $\mathrm{T}$ width; ridge present, perpendicular to T; not expanded, upper margin smooth; distally slightly projected.

Paratype female num. CRBA 1736. Figs 10-11. All characters as in male except: Carapace $3.26 \mathrm{~mm}$ long; maximum width $2.7 \mathrm{~mm}$; minimum width $1.76 \mathrm{~mm}$. Brownish orange, darkened at borders; slightly foveate at borders, wrinkled at middle, covered with tiny granulations. AME diameter $0.19 \mathrm{~mm}$; PLE $0.18 \mathrm{~mm}$; PME $0.16 \mathrm{~mm}$; AME slightly back from frontal border, separated from one another by about $2 / 3$ diameter, close to PLE; PME very close to each other, about 2/5 PME diameter from PLE. Sternum orange, darkened on borders; very slightly wrinkled, mainly between legs and frontal border.

Chelicerae $1.5 \mathrm{~mm}$ long, fang long, $1.33 \mathrm{~mm}$; basal segment proximal dorsal, ventral side scantly covered with piligerous granulations. Legs orange. Lengths of female described above: fe1 $2.5 \mathrm{~mm}$ (all measurements in mm); pal 1.56; ti1 2.04; me1 1.84; ta1 0.48; total 8.42; fe2 2.35; pa2 1.48; ti2 1.94; me2 1.79; ta2 0.51; total 8.06; fe3 1.84; pa3 1.07; ti3 1.33; me3 1.58; ta3 0.51; total 6.32; fe4 2.35; pa4 1.33; ti4 1.89; me4 2.24; ta4 0.56; total 8.36; fe Pdp 1.43; pa Pdp 0.66; ti Pdp 0.77; ta Pdp 0.79; total 3.65; relative length $1>4>2>3$. Spination: tb3d spines arranged in two bands; proximal 0-1.0.0; distal 1.0.0; tb3v spines arranged in one band; proximal 0.1.0; with two terminal spines. Tb4d spines spineless; tb4v spines arranged in one band; proximal 0.1.0; with two terminal spines.

Abdomen $3.73 \mathrm{~mm}$ long. Abdominal dorsal hairs $0.07 \mathrm{~mm}$ long; thin, curved, not compressed, pointed; uniformly, thickly distributed. Vulva DA (Fig. 10) clearly distinguishable from VA; DA slightly wider than long; DF wide in dorsal view. MF margins not fused, poorly developed, membranous. VA rectangle-like; frontal region completely sclerotized (Fig. 11); posterior region internal margin sclerotized, forming two stripes fused at the anterior part, diverging backwards; AVD absent. S attachment not projected under VA; arms as long as DA, slightly curved; tips not projected; neck as wide as arms. TB usual shape.

Variation. Carapace ranges in length from $2.37 \mathrm{~mm}$ to $3.77 \mathrm{~mm}$, males $(\mathrm{n}=2) 2.42$ 2.60, female $(\mathrm{n}=10)$ average 3.14 (2.37-3.77). Females from Supramonte di Oliena are significantly smaller (2.37-2.72) than those from Dorgali and Sa Oche. Male $(n=2)$ leg spination reduced compared to females. Spination variability summarised in Table 3.

Distribution. Known from several localities around the Supramonte region, a mountain and highland range in Sardinia, lying in the north-western part of the Gulf of Orosei.

Table 3. Intraspecific spination variability in D. jana sp. n.

\begin{tabular}{lllll}
\hline & Proximal & Medio-proximal & Medio-distal & Distal \\
\hline Tibia 3 dorsal & $0-1.0 .0$ & 0 & 0 & 1.0 .0 \\
\hline Tibia 4 dorsal & 0 & 0 & 0 & 0 \\
\hline Tibia 3 ventral & 0 & 0 & 0 & 1.0 .0 \\
\hline Tibia 4 ventral & 0.1 .0 & 0 & 0 & 1.0 .1 \\
\hline
\end{tabular}




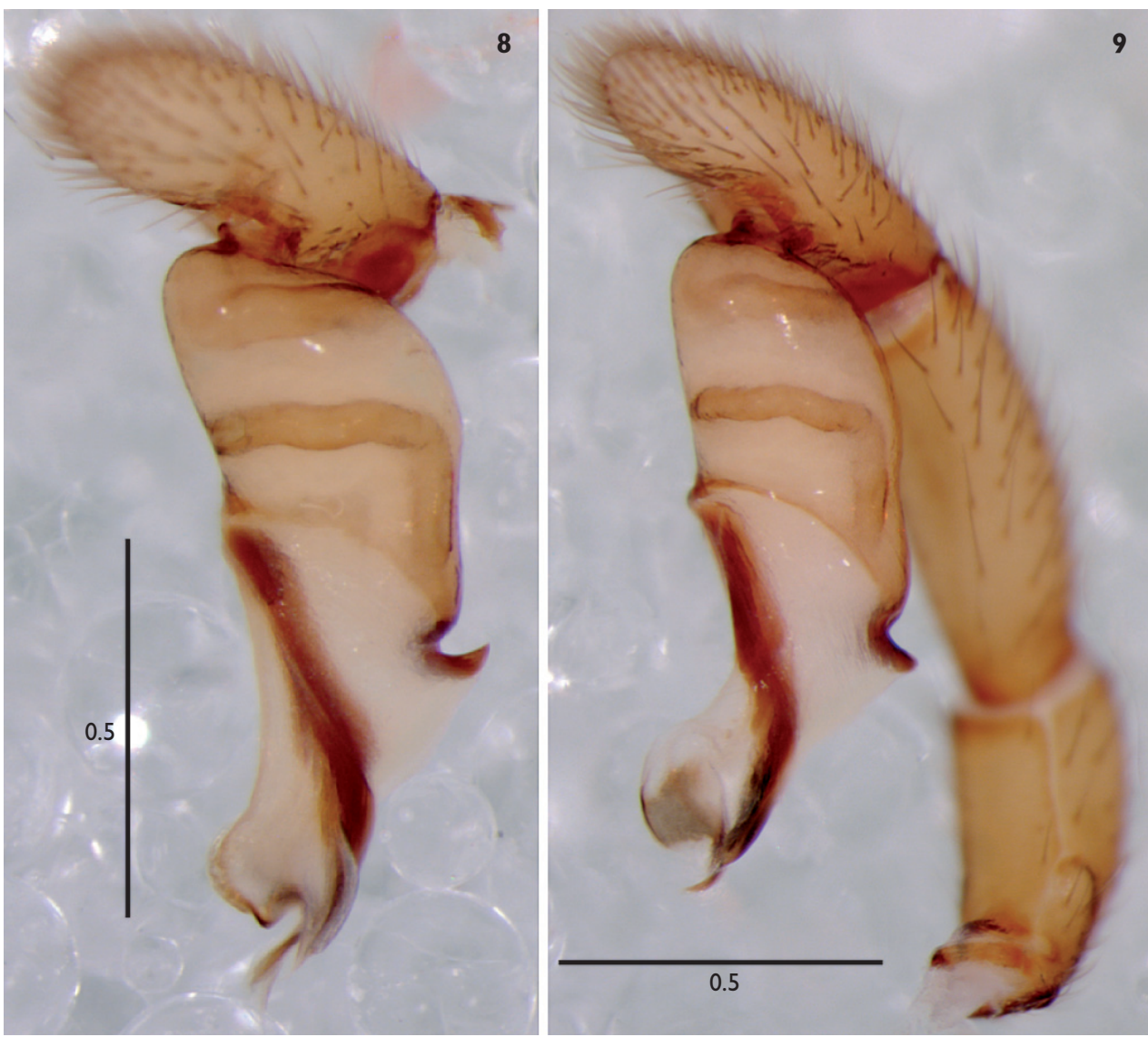

Figures 8-9. Left male palp, retrolateral view: 8 D. jana sp. n. holotype 9 D. shardana sp. n. holotype.

\section{Dysdera shardana Opatova \& Arnedo, sp. n.}

urn:lsid:zoobank.org:act:0D4FFE8A-AA79-4F64-9420-C9AC902A612A

Figs 5, 7, 9, 12-13, 19-22

Dysdera kollari Grasshoff, 1959: 219, figs 6 [ð̊] (NO Torralba, SO Cuglieri, S Cuglieri). Schult, 1983: 69-84, fig. 8 [ð] (same specimens as Grasshoff, 1959). Misidentification.

Type material. Holotype: male: Italy, Sardinia, Oristano, Morgongiori, Is Benas recreation area, Mt. Arci, 39.7606N, 8.76062E, 566 m, mixed Pinus and Quercus forest, 15.X.2005, M. Arnedo and M. Mejía-Chang leg. (CRBA001246).

Paratypes: 1 female (CRBA001246), 1 female (CRBA001247, DNA extraction K477), 2 juvs (CRBA001713, CRBA001714, DNA extraction LB297) same data and collectors.

Additional material examined. Italy: Sardinia: Cagliari: Fluminimaggiore, Is Arenas, under Quercus ilex; 800 m; G. Gardini leg. 29.III.1991, 1 ઊ (CG); Flumini- 
maggiore, Tempio di Antas, under Quercus ilex; 360 m; G. Gardini leg. 29.III.1991, 1 ㅇ (CG). Nuoro, Aritzo, Castagneto Geratzia, Mt. Gennargentu; 39.96846N 9.19782E; 867 m; Castaneus and Quercus suber forest; 17.X.2005; M. Arnedo, M. Mejía-Chang $\&$ G. Giribet leg. (1ㅇ CRBA001262 cryo-collection, DNA extraction LB303, 1 우 CRBA001710 cryo-collection, DNA extraction LB304, 10 CRBA0001263 cryocollection, DNA extraction LB305, 19 CRBA0001711 cryo-collection, DNA extraction LB306); Desulo, rd. to Fonni, Mt. Gennargentu; 40.05645N 9.22955E; 1146 m; Quercus pubens forest; 17.X.2005; M. Arnedo, M. Mejía-Chang and G. Giribet

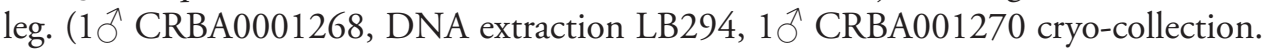
DNA extraction LB307, 1ð CRBA001712 cryo-collection. DNA extraction LB308);

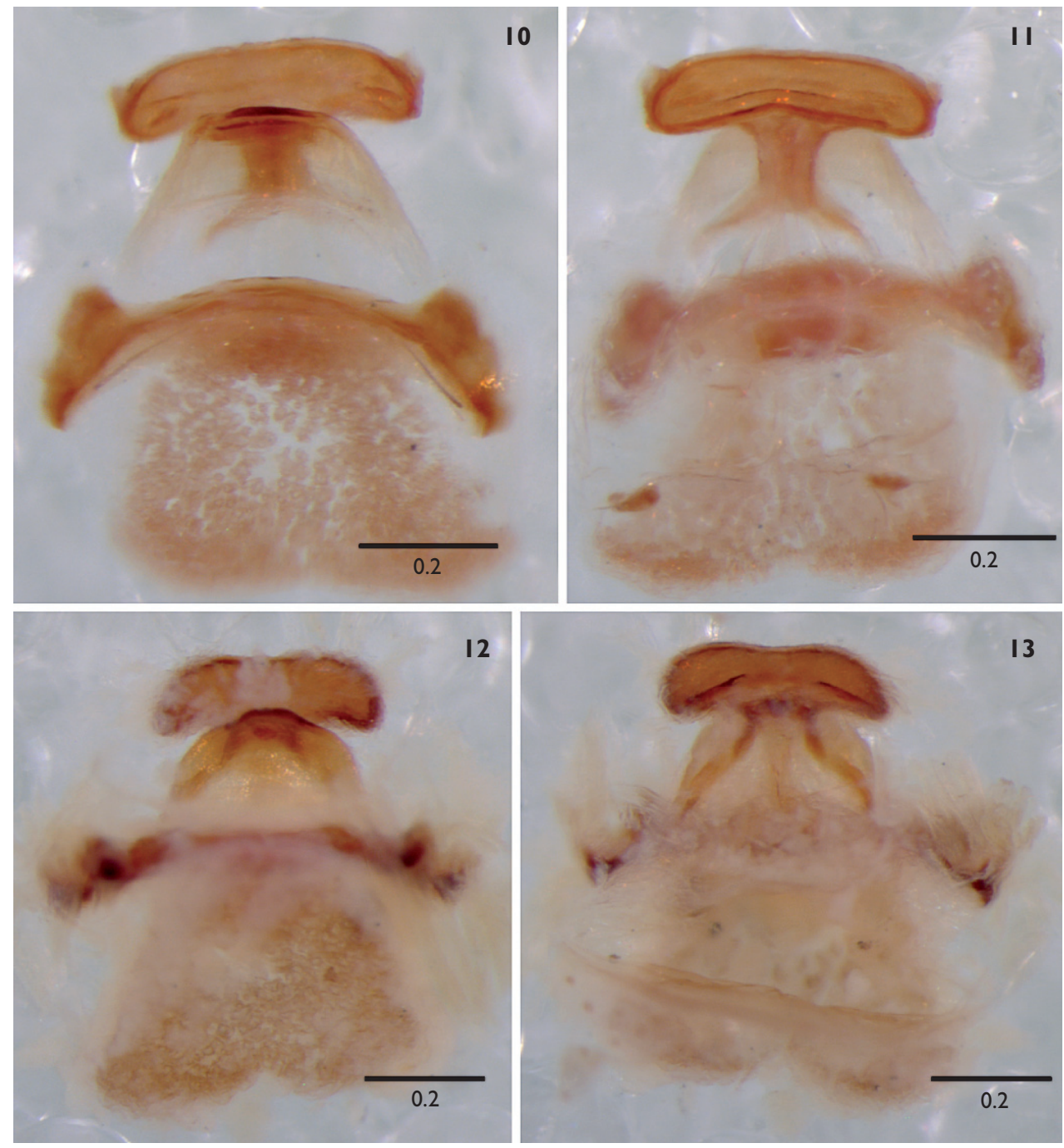

Figures I0-I3. D. jana sp. n. paratype female $\mathbf{I 0}$ vulva, dorsal view II vulva, ventral view. $D$. shardana sp. n. paratype female $\mathbf{I} \mathbf{2}$ vulva, dorsal view $\mathbf{I} \mathbf{3}$ vulva, ventral view. 
Macomer, Mt. S. Antonio, A. Vigna leg. 2.V.1967, 1 § (MCVR). Oristano, Cuglieri, rd. to San Leonardo 7 Fuentes, Mt. Ferru; 40.17931N 8.58544E; 587 m; dry, open Quercus forest; 14.X.2005; M. Arnedo and M. Mejía-Chang leg. (1 $q$ CRBA001238, cryo-collection, DNA extraction LB295); nearby S. Leonardo 7 Fuentes, Mt. Ferru, 40.20362N 8.68969E; $699 \mathrm{~m}$; old crops and open forest Quercus and Rubus; 14.X.2005; M. Arnedo \& M. Mejía-Chang leg. (1우 CRBA001240 cryo-collection,
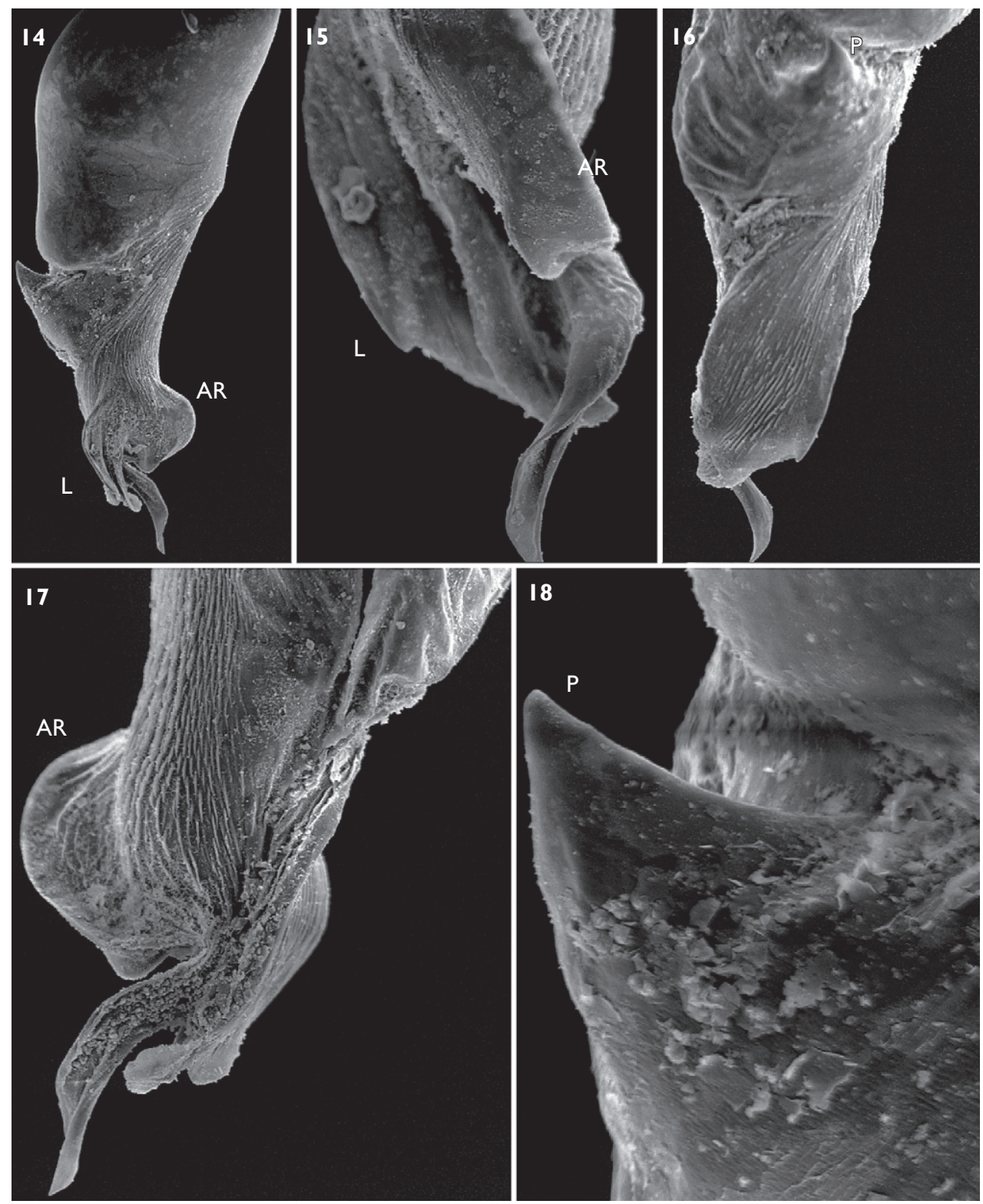

Figures I4-I8. $D$. jana sp. n. holotype, right male bulb $\mathbf{1 4}$ prolateral view, general I5 anterior view $\mathbf{1 6}$ posterior view $\mathbf{1 7}$ retrolateral view $\mathbf{1 8} \mathrm{P}$, prolateral view. 
DNA extraction LB296, 1 CRBA001707 cryo-collection, DNA extraction LB299, 1juv. CRBA001708 cryo-collection, DNA extraction LB300,); Morgongiori, Bruncu Mutzuis, 39.77145N 8.74666E; $761 \mathrm{~m}$; open Quercus forest w/ mosses; 15.X.2005; M. Arnedo \& M. Mejía-Chang leg. (1sub ${ }^{\lambda}$ CRBA001256, cryo-collection, DNA extraction LB301)
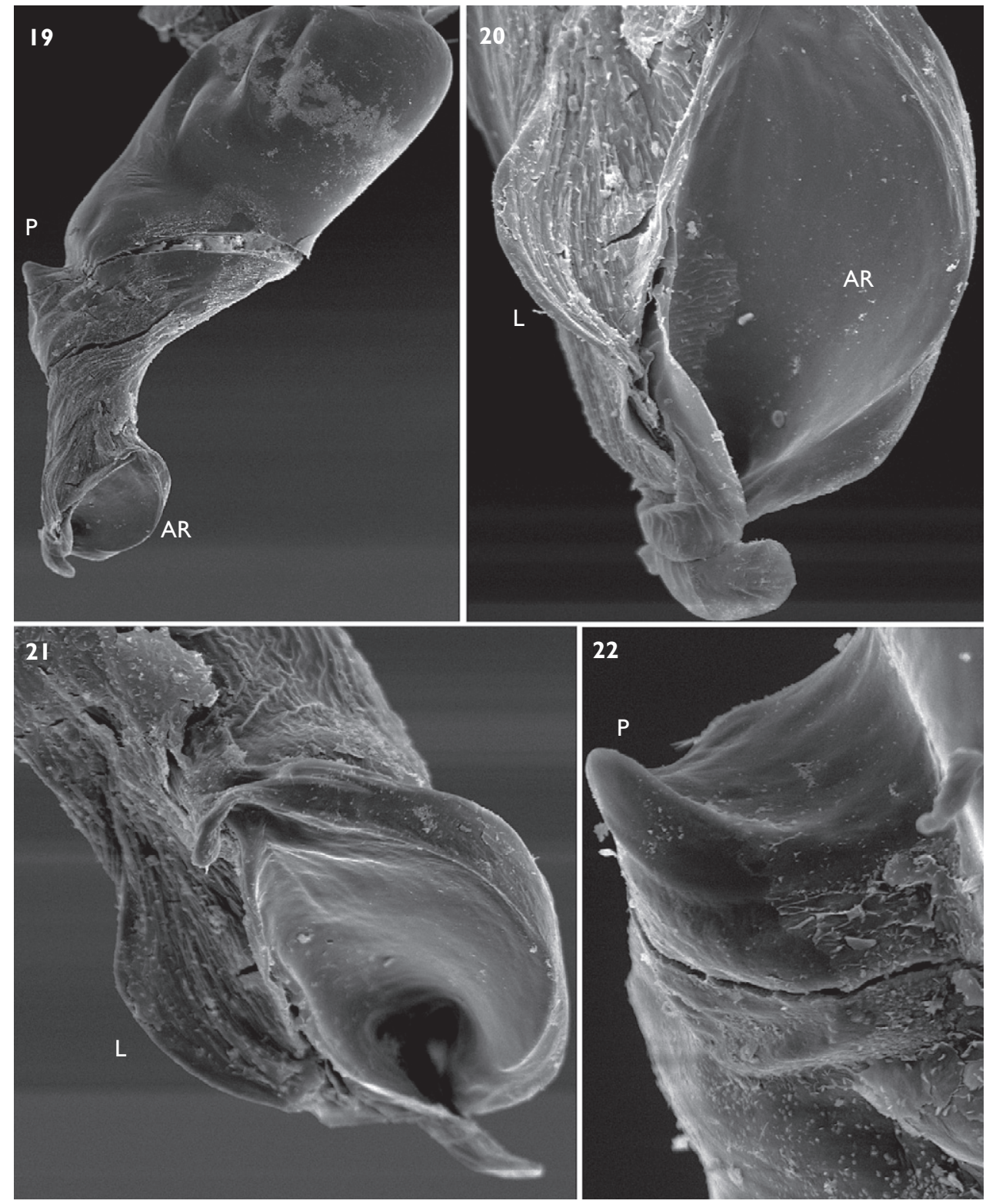

Figures 19-22. D. shardana holotype, right male bulb 19 prolateral view, general 20 prolateral view, tip detail 2 I anterior view 22 P, prolateral view. 
Diagnosis. Dysdera shardana sp. n. differs from continental species of the erythrina group in the shape of the posterior-distal part of the tegulum, which is expanded in the continental species. In addition, continental females of the erythrina group exhibit a characteristic hourglass-shaped spermatheca, which is very attenuated in D. shardana sp. $n$. It can also be distinguished from $D$. erythrina and D. erythrina provincialis by the lateral concave shape of the chelicera and a heavily wrinkled (foveate) carapace (Figs 5, 7). It differs from D. jana sp. n., also from Sardinia, in the presence of dorsal spines on tibia 4, the position and length of the finger-like process on the tip of the male bulb (compare Figs 15 and 21), and by the fusion of the anterior sclerotised stripes of the vulva VA (compare Figs 9 and 11).

Etymology. The name in apposition refers to the Shardana people, one of several groups of "Sea Peoples" that appear in fragmentary historical records (Egyptian inscriptions) for the Mediterranean region in the second millennium B.C. According to some scholars they settled in Sardinia after the period of Ramses III (around 1180 B.C.).

Description. Holotype male num. CRBA 1246. Figs 5, 7, 9, 19-22. Carapace (Fig. 5) $3.01 \mathrm{~mm}$ long; maximum width $2.35 \mathrm{~mm}$; minimum width $1.68 \mathrm{~mm}$. Dark red, darkened at borders; foveate at borders, slightly wrinkled in the middle, covered with small black grains. Frontal border roughly round, from $1 / 2$ to $3 / 5$ carapace length; anterior lateral borders parallel; rounded at maximum dorsal width, back lateral borders straight; back margin wide, straight. AME diameter $0.18 \mathrm{~mm}$; PLE $0.18 \mathrm{~mm}$; PME $0.16 \mathrm{~mm}$; AME slightly backwards from frontal border, separated from one another by about 2/3 diameter, close to PLE; PME close to each other, less than 1/4 PME diameter from PLE. Labium trapezoid-shaped, base wider than distal part; longer than wide at base; semicircular groove at tip. Sternum brownish orange, darkened on borders; wrinkled; uniformly covered in slender black hairs.

Chelicerae $1.2 \mathrm{~mm}$ long, about $2 / 5$ of carapace length in dorsal view; fang long, $1.22 \mathrm{~mm}$; basal segment proximal dorsal, ventral side scantly covered with piligerous granulations; concave-shaped in lateral view (Fig. 7). Chelicera inner groove long, about $1 / 2$ cheliceral length; armed with three teeth and lamina at base; $\mathrm{B}=\mathrm{M}>\mathrm{D}$; $\mathrm{D}$ triangular, slightly below groove midpoint; B close to basal lamina; M close to B. Legs yellow. Lengths of male described above: fe1 $2.3 \mathrm{~mm}$ (all measurements in $\mathrm{mm}$ ); pa1 1.3; ti1 1.84; me1 1.66; ta1 0.48; total 7.57; fe2 2.09; pa2 1.22; ti2 1.71; me2 1.58; ta2 0.51; total 7.11; fe3 1.58; pa3 0.87; ti3 1.07; me3 1.43; ta3 0.41; total 5.31; fe4 2.09; pa4 1.17; ti4 1.68; me4 1.89; ta4 0.51; total 7.34; fe Pdp 1.22; pa Pdp 0.66; ti Pdp 0.66; ta Pdp 0.71; total 3.26; relative length: $1>4>2>3$. Spination: leg1, leg2 spineless; fe3d spineless; pa3 spineless; tb3d spines arranged in two bands; proximal 1.0.0; distal 1.0.0; tb $3 \mathrm{v}$ spines arranged in one band; proximal 0.1.0; with one prolateral spine on left leg, and two terminal on right leg. Fe4d spineless; pa4 spineless; tb4d spines arranged in two bands; proximal 1.0-1.1; distal 0.0.0-1; tb4v spines arranged in one band; proximal 0.1.0; with two terminal spines. Dorsal side of frontal legs, ventral side of palp covered with hairs. Claws with eight teeth or less; hardly larger than claw width.

Abdomen $3.26 \mathrm{~mm}$ long; cream-coloured; cylindrical. Abdominal dorsal hairs $0.13 \mathrm{~mm}$ long; thin, curved, not compressed, pointed; uniformly thickly distributed. 
Male copulatory bulb (Fig. 9) T slightly shorter than DD; external, internal distal border sloped backwards. DD bent about $45^{\circ}$ in lateral view; internal distal border not expanded. IS, ES equally developed; IS truncated at DD middle part. DD tip (Figs 19-21) straight in lateral view; AR present, parallel to DD; finger-like distal projection at AR retrolateral side, shorter than AR length. $\mathrm{C}$ absent. AC absent. LF absent. L reduced to distal part. LA absent. F absent. AL absent. P (Fig. 22) fused to T; sloped forming an angle of about $135^{\circ}$ to $\mathrm{T}$ in lateral view; lateral length about $1 / 4$ of $\mathrm{T}$ width; ridge present, parallel to T; not expanded, upper margin smooth; not distally projected; back margin slightly folded towards internal side.

Paratype female num. CRBA 1246. Figs 12-13. All characters as in male except: Carapace $3.19 \mathrm{~mm}$ long; maximum width $2.55 \mathrm{~mm}$; minimum width $1.68 \mathrm{~mm}$. AME diameter $0.18 \mathrm{~mm}$; PLE $0.19 \mathrm{~mm}$; PME $0.16 \mathrm{~mm}$; AME slightly back from frontal border, separated from one another by about $2 / 3$ diameter, touching PLE; PME very close to each other, less than 1/4 PME diameter from PLE. Sternum very slightly wrinkled, mainly between legs and frontal border.

Chelicerae $1.38 \mathrm{~mm}$ long; fang $1.48 \mathrm{~mm}$; basal segment proximal dorsal side scantly covered with piligerous granulations. Chelicera armed with three teeth and lamina at base; $\mathrm{M}>\mathrm{B}=\mathrm{D}$. Legs orange. Lengths of female described above: fe1 2.22 $\mathrm{mm}$ (all measurements in $\mathrm{mm}$ ); pa1 1.35; ti1 1.73; me1 1.58; ta1 0.46; total 7.34; fe2 2.04; pa2 1.28; ti2 1.68; me2 1.53; ta2 0.48; total 7.01; fe3 1.66; pa3 0.92; ti3 1.15; me3 1.38; ta3 0.41; total 5.51; fe4 2.27; pa4 1.22; ti4 1.79; me4 1.89; ta4 0.48; total 7.65; fe Pdp 1.17; pa Pdp 0.61; ti Pdp 0.61; ta Pdp 0.71; total 3.11; relative length $4>1>2>3$. Spination: tb3d spines arranged in two bands; proximal 1.0.0; distal 1.0.0; tb3 $\mathrm{v}$ with two terminal spines. Tb4d spines arranged in one band; proximal $1.0 .1 ; \mathrm{tb} 4 \mathrm{v}$ spines arranged in one band; proximal 0.1.0; with two terminal spines.

Abdomen $4.56 \mathrm{~mm}$ long. Abdominal dorsal hairs $0.14 \mathrm{~mm}$ long; medium-sized, curved, compressed, pointed; uniformly, thickly distributed. Vulva (Figs 12-13) DA clearly distinguishable from VA; DA slightly wider than long; DF wide in dorsal view. MF margins not fused, poorly developed, membranous (Fig. 12). VA rectangle-like, pointed expansion at middle frontal part (Fig. 13); frontal region completely sclerotized; posterior region internal margin sclerotized, forming two divergent stripes; AVD absent. $S$ attachment not projected under VA; arms as long as DA, slightly curved; tips not projected; neck hardly visible. TB usual shape.

Variation. Carapace ranges in length from $2.50 \mathrm{~mm}$ to $3.42 \mathrm{~mm}$, males $(\mathrm{n}=7)$ average 2.79 (2.50-3.06), female $(n=8)$ average 3.07 (2.68-3.42). In general male legs

Table 4. Intraspecific spination variability in D. shardana sp. n.

\begin{tabular}{lllll}
\hline & Proximal & Medio-proximal & Medio-distal & Distal \\
\hline Tibia 3 dorsal & 1.0 .0 & 0 & 0 & 1.0 .0 \\
\hline Tibia 4 dorsal & $0-1.0-1.1$ & 0 & 0 & $0.0 .0-1$ \\
\hline Tibia 3 ventral & $0.0-1.0$ & 0 & 0 & $1.0 .0-1$ \\
\hline Tibia 4 ventral & $0.0-1.0$ & 0 & 0 & $1.0 .0-1$ \\
\hline
\end{tabular}


bear fewer spines that female legs, one male form Mt. S. Antonio representing an extreme case of reduced spination. Spination variability summarised in Table 4.

Distribution. Known from several localities around the western half of Sardinia, and also in the Gennargentu region on the central-eastern side of the island, spanning from 360 to above 1100 m elevation.

\section{Discussion}

Molecular phylogenetic analyses unambiguously support the close relationship of Dysdera shardana sp. $\mathrm{n}$. with the species of the erythrina group. Morphological synapomorphies for this clade include a large, semicircular expansion (AR) at the DD tip, running parallel to the bulb proximal-distal axis and a bilobular, granulated posterior diverticulum in the female vulva. Both $D$. shardana sp. n. and $D$. jana sp. n. exhibit a regular-shaped tegulum. This suggests that the particular shape of the tegulum with a mid-part constraint and an expansion around the $\mathrm{P}$ region is most likely a synapomorphy of the clade formed by $D$. lantosquensis and D. erythrina. The erythrina group was not defined in cladistic terms and hence it is not possible to assess its limits. The taxonomic sampling of the phylogenetic analysis conducted in this study included two species closely resembling those originally proposed to be part of the erythrina group, namely $D$. cf. inermis (closely similar to $D$. fuscipes) and $D$. lusitanica (resembling $D$. veigai). The phylogenetic analyses revealed that they are not closely related to $D$. erythrina. Deeleman-Reinhold and Deeleman (1988) did not justify the inclusion of $D$. fuscipes and $D$. veigai species into the erythrina group and thus it is difficult to evaluate convergence in morphological traits. All these species, however, share a particular shape of the $\mathrm{P}$, which is in most cases short and with the proximal margin parallel, instead of perpendicular, to the proximal-distal axis of the bulb. Close examination of this structure, however reveals, obvious differences among the species (e.g., the particular shape observed in the D. lantosquensis / D. erythrina clade is probably synapomorphic for this group). The eastern Iberian species $D$. valentina was included in the analyses based on the similarities in the distal part of the male bulb DD to D. erythrina. All analyses support (although only marginally under parsimony and maximum likelihood) the sister group relationship of $D$. valentina with the $D$. shardana sp. n. / D. erythrina clade, suggesting that the presence of a long, arch-like expansion on the anterior-distal side of the DD, running parallel to a short L (see Ribera 2004, Figs 1A-B) could constitute a synapomorphy of a more inclusive clade that would also embrace the erythrina group. More morphological comparative data and new phylogenetic analyses based on more exhaustive taxonomic sampling would be required to confirm the latter suggestion.

Based on morphological evidence, there is little doubt that the two new Sardinian Dysdera species are closely related. They are extremely similar in somatic morphology (some minor differences in leg spination) and share at least one exclusive character: the presence of a finger-like projection at the tip of the male bulb (although it is not completely clear whether the process actually grows from the same position, see diagnosis). 
Unfortunately, the lack of genetic data for $D$. jana sp. n. precludes discerning whether the two endemics are sister species or whether one of them is actually more closely related to the D. erythrina /D. lantosquensis clade. Examples of local diversification in Sardinia have been reported in other ground-dwelling animals. The cave beetle genera Ovobathysciola and Patriziella form a monophyletic group that includes six endemic species in Sardinia. Molecular clock analysis suggests that separation among the Ovobathysciola / Patriziella species started about 16 to 10 m.a., assuming that the clade originated as a result of the split of the Corsico-Sardinian plate from the Iberian peninsula ( -30 m.a.) (Caccone and Sbordoni 2001). The Hydromantes cave salamanders, on the other hand, include five endemic lineages in Sardinia, which have been recently shown to form a paraphyletic group with regard to closest relatives in south-eastern France and northern-central Italy (Carranza et al. 2008). In this case, molecular time estimates suggest that the Messinian Salinity Crisis facilitated the two independent colonisation events that gave rise to present day Sardinian endemics (although a single colonisation of the island followed by a back colonisation of the mainland is an equally parsimonious explanation). The unresolved phylogenetic position of D. jana sp. n. hinders distinguishing between a scenario of a single colonisation of Sardinia followed by in situ speciation of the two new Dysdera species from a scenario with a colonisation of Sardinia by the common ancestor of the D. shardana sp. n. / D. erythrina clade followed by back colonisation of the mainland. Regardless of the scenario, time estimates clearly suggest that the split of $D$. shardana sp. n. from mainland relatives post-dates the opening of the western Mediterranean basin. Time estimates of the split of $D$. shardana sp. $\mathrm{n}$. and of the diversification of the D. erythrina / D. lantosquensis clade are close enough to the Messinian Salinity Crisis time period to suggest that this geological event may have played a role in the origin of these lineages, as has also been proposed for the harvestmen genus Trogulus (Schönhofer and Martens 2008). Confidence intervals of the time estimates, however, are too large to rule out other alternative scenarios. Moreover, it has been shown based on mitochondrial substitution rates that transGibraltar lineage divergences in the scorpion Buthus occitanus predate the opening of the strait of Gibraltar (Gantenbein and Largiader 2003), which opens the door to the possibility that our calibration point is too young and hence the time of colonization of Sardinia is an underestimation.

At this stage, it is not clear what factors may have prompted the speciation of the two new Sardinian endemics. The two species show allopatric distribution, generally associated to middle $(500 \mathrm{~m})$ and high elevations $(1000 \mathrm{~m})$. D. jana sp. n. seems to have a narrow distribution, restricted to the Supramonte region, while D. shardana sp. n. is widespread across most of the islands, except for the northern and southernmost areas (Mt. Limbara and Sette Fratelli, respectively). Interestingly, species of the cave-dwelling beetle lineage Ovobathysciola / Patriziella show a very similar geographic distribution pattern to $D$. jana sp. n. (O. graffiti is endemic to the Supramonte region) and D. shardana sp. n. (the rest of the Ovobathysciola / Patriziella species are found in Mt. Arci, Mt. Ferru and Gennargentu), although with contrasting levels of species diversity and phylogenetic relationships (compare fig. 2 in Caccone and Sbordoni 2001 
with our Fig. 3). Genetic analysis of several D. shardana sp. n. populations, however, revealed strong phylogeographic patterns in this species. Populations from Mt. Arci form an independent network (i.e., highly divergent haplotypes) from those sampled from Mt. Ferru and Gennargentu, which are also separated (the southernmost known populations on Sulcis-Iglesiente could not be analysed genetically). This observation does not necessarily imply that the former haplotype groups should be considered independent evolutionary lineages, but it does suggest that there are environmental factors (e.g., unsuitable lowland habitat due to warmer climatic conditions) restricting gene flow across geographic areas separated by just $50 \mathrm{~km}$. Environmental restrictions to gene flow could eventually lead to speciation and hence explain the presence of two sibling species of the erythrina group on Sardinia.

\section{Conclusion}

Two new species of the woodlouse-hunter spider genus Dysdera are described from Sardinia. Phylogenetic evidence and morphological features suggest that they are closely related to the type species of the genus $D$. erythrina. Time estimates reject an Oligocene origin of the new Dysdera species and instead suggest that the Messinian Salinity Crisis shaped the diversification of Sardinian endemics and their closest relatives. Deep genetic divergences and population structure in Dysdera shardana sp. n. identifies restriction to gene flow due to environmental factors as the most plausible explanation for local speciation events.

\section{Acknowledgements}

We would like to thank Mónica Mejía-Chang and Gonzalo Giribet for their invaluable assistance in the field. We are very grateful to Leticia Bidegaray-Batista for conducting part of the labwork. Gonzalo Giribet and an anonymous reviewer provided valuable comments that improved the final version of the paper. Funding was provided by grants from the Spanish Ministerio de Educación y Ciencia (CGL2006-08617/BOS to $\mathrm{MA}$ ) and the European Union-funded ERASMUS programme (VO). Further funding support was provided by an ICREA Academia award for excellence in research from the Generalitat de Catalunya to MA.

\section{References}

Akaike H (1973) Information theory as an extension of the maximum likelihood principle. In: Petrov BN, Csaki F (Eds) Second International Symposium on Information Theory. Akademiai Kiado, Budapest, 1-434 pp.

Alvarez W (1972) Rotation of the Corsica-Sardinia microplate. Nature 235: 103-105. 
Alvarez W (1974) Sardinia and Corsica one microplate or two? Rendiconti Seminari Facoltá di Scienze Universitá di Cagliari.

Arias C, Azzararoli A, Bigazzi G, Bonadonna FP (1980) Magnetostratigraphy and PliocenePleistocene boundary in Italy. Quarternary Research 13: 65-74.

Arnedo MA, Oromí P, Ribera C (2000) Systematics of the genus Dysdera (Araneae, Dysderidae) in the Eastern Canaries. Journal of Arachnology 28: 261-292.

Arnedo MA, Ribera C (1997) Radiation of the genus Dysdera (Araneae, Haplogynae, Dysderidae) in the Canary Islands: The island of Gran Canaria. Zoologica Scripta 26: 205-243.

Arnedo MA, Ribera C (1999) Radiation of the genus Dysdera (Araneae, Dysderidae) in the Canary Islands: The island of Tenerife. Journal of Arachnology 27: 604-662.

Bacchetta G, Mandis G, Pontecorvo C (2007) Contribution to the knowledge of the endemic vascular flora of Sulcis (SW Sardinia - Italy). Bocconea 21: 155-166.

Blondel J, Aronson J (1999) Biology and wildlife of the Mediterranean region. Oxford University Press, Oxford, New York, xxii, 328 pp.

Caccone A, Sbordoni V (2001) Molecular biogeography of cave life: a study using mitochondrial DNA from bathysciine beetles. Evolution 55: 122-130.

Carranza S, Arnold EN (2003) History of West Mediterranean newts, Pleurodeles (Amphibia: Salamandridae), inferred from old and recent DNA sequences. Systematics and Biodiversity 1: 327-338.

Carranza S, Romano A, Arnold EN, Sotgiu G (2008) Biogeography and evolution of European cave salamanders, Hydromantes (Urodela: Plethodontidae), inferred from mtDNA sequences. Journal of Biogeography 35: 724-738.

Chyzer K, Kulczyński W (1897) Araneae Hungariae, Budapest 2: 151-366.

Clement M, Posada D, Crandall KA (2000) TCS: a computer program to estimate gene genealogies. Molecular Ecology 9: 1657-1660.

Costa A (1885) Notizie ed osservazione sulla geo-fauna sarda. IV. Atti delle Reale Accademia delle Scienze Fisiche e Matematiche di Napoli (2) 1: 1-31.

Deeleman-Reinhold CL, Deeleman PR (1988) Revision des Dysderinae. Tijdschrift voor Entomologie 131: 141-269.

Drummond AJ, Ashton B, Cheung M, Heled J, Kearse M, Moir R, Stones-Havas S, Thierer T, Wilson A (2009) GENEIOUS v. 4.5. Available at http://www.geneious.com.

Gantenbein B (2004) The genetic population structure of Buthus occitanus (Scorpiones: Buthidae) across the Strait of Gibraltar: calibrating a molecular clock using nuclear allozyme variation. Biological Journal of the Linnean Society 81: 519-534.

Gantenbein B, Largiader CR (2003) The phylogeographic importance of the Strait of Gibraltar as a gene flow barrier in terrestrial arthropods: a case study with the scorpion Buthus occitanus as model organism. Molecular Phylogenetics and Evolution 28: 119-130.

Gasparo F (2004) Descrizione di Dysdera arganoi n. sp. della Calabria meridionale (Araneae, Dysderidae). Fragmenta Entomologica 36: 93-102.

Goloboff PA, Farris JS, Nixon KC (2003) TNT: Tree Analysis Using New Technologies. Program and documentation available at http://www.zmuc.dk/public/phylogeny/TNT/.

Gómez-Zurita J (2004) Molecular systematics and time-scale for the evolution of Timarcha, a leaf-beetle genus with a disjunct Holarctic distribution. Molecular Phylogenetics and Evolution 32: 647-665. 
Grasshoff M (1959) Dysdera-Arten von Inseln der Mittelmeergebietes (Arachn., Araneae). Senckenbergiana biologica 40: 209-220.

Grill A, Casula P, Lecis R, Menken S (2007) Endemism in Sardinia. In: Weiss S, Ferrand N (Eds) Phylogeography of southern European refugia Evolutionary perspectives on the origins and conservation of European biodiversity. Springer, Dordrecht, 273-296.

Katoh K, Kuma Ki, Toh H, Miyata T (2005) MAFFT version 5: improvement in accuracy of multiple sequence alignment. Nucleic Acids Research 33: 511-518.

Katoh K, Misawa K, Kuma K, Miyata T (2002) MAFFT: a novel method for rapid multiple sequence alignment based on fast Fourier transform. Nucleic Acids Research 30: 3059-3066.

Krijgsman W, Hilgen FJ, Raffi I, Sierro FJ, Wilson DS (1999) Chronology, causes and progression of the Messinian Salinity Crisis. Nature 400: 652-655.

Loget N, Van Den Driessche J (2006) On the origin of the Strait of Gibraltar. Sedimentary Geology 188-189: 341-356.

Loget N, Van Den Driessche J, Davy P (2005) How did the Messinian Salinity Crisis end? Terra Nova 17: 414-419.

Macías-Hernández N, Oromí P, Arnedo MA (2008) Patterns of diversification on old volcanic islands as revealed by the woodlouse-hunter spider genus Dysdera (Araneae, Dysderidae) in the eastern Canary Islands. Biological Journal of the Linnean Society 94: 589-615.

Medail F, Quezel P (1999) Biodiversity Hotspots in the Mediterranean Basin: Setting Global Conservation Priorities. Conservation Biology 13: 1510-1513.

Myers N, Mittermeier RA, Mittermeier CC, da Fonseca GA, Kent J (2000) Biodiversity hotspots for conservation priorities. Nature 403: 853-858.

Nixon KC (2002) WinClada. ver. 1.00.08. Published by the Author, Ithaca, New York.

Nylander JAA, Ronquist F, Huelsenbeck JP, Nieves-Aldrey JL (2004) Bayesian phylogenetic analysis of combined data. Systematic Biology 53: 47-67.

Platnick NI (2009) The World Spider Catalog. v. 9.5 ed. American Museum of Natural History, New York. online at http://research.amnh.org/entomology/spiders/catalog/GENERIC. IND.html [accessed 24.II.09]

Pons J, Vogler A (2006) Size, frequency, and phylogenetic signal of multiple-residue indels in sequence alignment introns. Cladistics 22: 144-156.

Posada D (2008) jModelTest: Phylogenetic Model Averaging. Molecular Biology and Evolution 25: 1253-1256.

Rambaut A, Charleston M (2001) TREEEDIT. 1.0a8. http://evolve.zoo.ox.ac.uk

Rambaut A, Drummond AJ (2003) TRACER. 1.3. Available at http://tree.bio.ed.ac.uk/software/tracer/ [accessed on November 30th, 2007]

Řezáč M, Král J, Pekár S (2007) The spider genus Dysdera (Araneae, Dysderidae) in central Europe: revision and natural history. Journal of Arachnology 35: 432-462.

Ribera C (2004) Dysdera valentina sp. n. (Araneae, Dysderidae), a new species from Valencia province (Spain), with some additions to the cave dwelling fauna of the Iberian Peninsula. Revista Ibérica de Aracnología 9: 211-215.

Ronquist F, Huelsenbeck JP (2003) MrBayes 3: Bayesian phylogenetic inference under mixed models. Bioinformatics 19: 1572-1574. 
Rosenbaum G, Lister GS, Duboz C (2002) Reconstruction of the tectonic evolution of the western Mediterranean since the Oligocene. In: Rosenbaum G, Lister GS (Eds) Reconstruction of the evolution of the Alpine-Himalayan Orogen. Journal of the Virtual Explorer ISSUE, 107-126.

Sanderson MJ (2002) Estimating absolute rates of molecular evolution and divergence times: a penalized likelihood approach. Molecular Biology and Evolution 19: 101-109.

Sanderson MJ (2003) r8s: Inferring absolute rates of molecular evolution and divergence times in the absence of a molecular clock. Bioinformatics 19: 301-302.

Schönhofer AL, Martens J (2008) Revision of the genus Trogulus Latreille: the Trogulus coriziformis species-group of the western Mediterranean (Opiliones: Trogulidae). Invertebrate Systematics 22: 523-554.

Schult J (1983) Taster haplogyner Spinnen unter phylogenetischem Aspekt (Arachnida: Araneae). Verhandlungen des Naturwissenschaftlichen Vereins in Hamburg 26: 69-84.

Simmons MP, Ochoterena H (2000) Gaps as characters in sequence-based phylogenetic analyses. Systematic Biology 49: 369-381.

Stamatakis A (2006) RAxML-VI-HPC: maximum likelihood-based phylogenetic analyses with thousands of taxa and mixed models. Bioinformatics 22(21): 2688-2690.

Stoch F (2003) Checklist of the species of the Italian Fauna. On-line version 2.0. Italian Ministry of Environment Available at http://www.faunaitalia.it/checklist/

Tamura K, Dudley J, Nei M, Kumar S (2007) MEGA4: Molecular Evolutionary Genetics Analysis (MEGA) software version 4.0. Molecular Biology and Evolution 24: 1596-1599.

Young ND, Healy J (2003) GapCoder automates the use of indel characters in phylogenetic analysis. BMC Bioinformatics 4: 6 . 